Revista Destaques Acadêmicos, Lajeado, v. 9, n. 1, 2017. ISSN 2176-3070

DOI: http://dx.doi.org/10.22410/issn.2176-3070.v9i1a2017.1259

www.univates.br/revistas

\title{
DESAFIO DA MULHER NA GESTÃO DAS PROPRIEDADES RURAIS FAMILIARES DO MUNICÍPIO DE WESTFÁLIA/RS
}

\author{
Talita Halmenschlager Rhein ${ }^{1}$, Lizete Berrá
}

Resumo: A agricultura familiar, a qual é caracterizada pela participação de todos os membros da família na produção, tem grande importância para o desenvolvimento do país. Nos municípios do Vale do Taquari ela se destaca na maioria das propriedades. Em função dessa característica muito evidente foi escolhido o município de Westfália/RS, para realizar um estudo sobre a participação feminina na gestão das propriedades. $\mathrm{O}$ objetivo do estudo é analisar os principais desafios da mulher na gestão das propriedades rurais familiares. Junto a investigação foi identificado o perfil, a expectativa dos pais em relação ao seu papel, como se portam diante da gestão e as dificuldades que enfrentam. A metodologia utilizada para a coleta de dados é exploratória, qualitativa e quanto aos procedimentos técnicos o surwey, informações baseadas num interrogatório. Os dados foram obtidos através de uma entrevista semiestruturada, realizada com cinco mulheres que atuam nas propriedades rurais. A análise evidenciou que elas enfrentam desafios diários, necessitam ter planejamento das atividades, organizar a propriedade, ter controle de entradas, saídas, custos e resultados. E, além disso, ter a habilidade de conciliar os trabalhos produtivos com os trabalhos domésticos e exercer a função de ser mãe. Elas assumem junto com os demais membros da família as responsabilidades, direitos e deveres em relação à propriedade. O grupo de mulheres entrevistadas acompanham de forma satisfatória, as mudanças pela qual passa a sociedade atual, conquistando o seu espaço e fazendo frente às novas exigências e possibilidades.

Palavras-chave: Agricultura familiar. Gestão. Participação da mulher.

\section{INTRODUÇÃO}

No Brasil uma das primeiras atividades exploradas foi agricultura e a agropecuária. Os indígenas plantavam seus próprios alimentos para a sua subsistência e os imigrantes trouxeram outras variedades de produtos para

1 Acadêmica do curso de Administração - LFE em Negócios Agroindustriais pelo Centro Universitário UNIVATES.

2 Graduada em Administração pela Faculdade de Ciências Econômicas do Alto Taquari (1994). Mestre em Engenharia de Produção pela Universidade Federal de Santa Maria (2003). 
serem cultivados. Com o passar dos tempos, os cenários foram se modificando e a agropecuária passou a gerar desenvolvimento e crescimento. Passa a ser uma empresa rural, que necessita de administração e gerenciamento por parte dos envolvidos. O negócio precisa estar ativo e lucrativo a fim de cobrir os gastos, gerar reservas e fazer novos investimentos.

A agricultura familiar tem grande destaque pela sua forma de explorar a atividade. O próprio produtor executa e gerencia as tarefas da propriedade juntamente com a sua família. São considerados agricultores familiares os pequenos proprietários rurais, que têm como mão de obra essencialmente o núcleo familiar. Segundo o Ministério do Desenvolvimento Agrário no "Plano Safra da Agricultura Familiar 2012/2013", a agricultura familiar é responsável por produzir $70 \%$ dos alimentos consumidos no Brasil, responde por $38 \%$ da renda agropecuária e $75 \%$ da mão de obra do campo.

De forma geral desempenham um papel sócio-econômico de grande importância para o país, geração de emprego, renda as famílias, contribuem para a diminuição do êxodo rural, diversificação da produção e possibilidade de preservação do meio ambiente.

A maioria das unidades tem por objetivo crescer de forma sustentável, melhorar a qualidade de vida e viabilizar a permanência das futuras gerações. Mas, dentro do ambiente competitivo atual, os controles administrativos e de gestão são de suma importância.

Dependência das inovações e constantes adaptações ao ambiente organizacional os agronegócios precisam ter habilidade de se adaptar. A gestão administrativa com controles técnicos gera competitividade ao negócio e garantem o sucesso dos empreendimentos.

Na gestão das propriedades rurais, o homem normalmente é visto como o principal membro atuante desse segmento. Mas isso está mudando, elas, as mulheres, desempenham múltiplas funções e tarefas na organização interna. Realizam controles administrativos, tomam decisões, isso significa que participam das atividades de gerenciamento da propriedade.

Durante muitos anos os fatores físicos e biológicos, colocaram as mulheres em condições inferiores, sexo frágil. O temperamento mais paciente e compreensivo acabou por reforçar a desigualdade da mulher perante $o$ homem. A partir do século XIX, os movimentos feministas e as pesquisas sobre mulheres ganham outras perspectivas.

Atualmente as mulheres estão sendo alvo de variadas pesquisas, pela sua crescente inserção no mercado de trabalho. As relações sociais têm grande importância na agricultura familiar, pois interfere diretamente na divisão das tarefas, na gestão e na participação da família nas atividades da comunidade.

A pesquisa num âmbito atual, parte do princípio que mudanças e transformações ocorrem no espaço rural, nas últimas décadas houve um rearranjo nas unidades produtivas de base familiar. Utilizar o talento e o 
potencial, dividindo as tarefas e responsabilidades, dando vez às mulheres, oportunizando sua participação nas decisões e divisão igualitária dos lucros e capital. No momento que é posto em prática, agrega valor ao trabalho rural e ganha força competitiva, capaz de conduzir ao sucesso e sobrevivência com qualidade de vida.

Ao considerar que hoje as mulheres não são mais submissas ou incapazes, em relação ao sexo masculino, mas sim participam e têm uma posição importante e fundamental na posição hierárquica da propriedade, a questão problema da pesquisa é: quais são os principais desafios da mulher na gestão da propriedade rural familiar no município de Westfália/RS?

Diante do exposto, o presente trabalho tem como objetivo geral, analisar os principais desafios da mulher na gestão da propriedade rural familiar do município de Westfália/RS. E quanto aos objetivos específicos, identificar o seu perfil, identificar a expectativa dos pais em relação ao papel da mulher (filha) na propriedade, analisar como é a gestão das mulheres na propriedade e verificar as principais dificuldades dela na gestão da propriedade rural.

As propriedades em estudo estão situadas em Westfália/RS, município predominantemente de pequenas propriedades rurais familiares. Será uma pesquisa em profundidade com mulheres que atuam na gestão das propriedades rurais. A pesquisa para a analise das informações será dentro do período de agosto a outubro de 2016.

\section{ADMINISTRAÇÃO/GESTÃO}

Segundo Stoner e Freemann $(1999$, p. 4) "Administração é o processo de planejar, organizar, liderar e controlar o trabalho dos membros da organização, e de usar os recursos disponíveis da organização para alcançar os objetivos estabelecidos".

Dentro do contexto de administração, como uma ciência a ser estudada, tem como objetivo conhecer os vários temas que envolvem o campo, reconhecer a área que mais identifica e as técnicas mais adequadas para a solução eficaz dos problemas. É o processo no qual o administrador cria, dirige, mantém, opera e controla uma organização (EUNICE LACAVA KWASNICKA, 1995).

Uma organização é uma entidade formada por duas ou mais pessoas, que trabalham juntas de modo estruturado para alcançar um objetivo. Segundo Montana (2003, p. 170), "organizar é o processo de reunir recursos físicos e principalmente humanos, essenciais a consecução dos objetivos de uma empresa". Em função de aspectos particulares de cada organização, o administrador ira definir as estratégias, dimensionar os recursos, planejar a aplicação, resolver problemas e gerar inovações e competitividade.

Chiavenato (2014) explica que o administrador não é analisado nas organizações apenas pelo seu conhecimento técnico em administração, mas sim pela sua competência, seu modo de agir, suas atitudes, habilidades e 
comprometimento no trabalho. Não existe uma maneira de administrar uma organização o importante é que o administrador saiba conduzir os trabalhos para alcançar os objetivos propostos.

Os gestores exercem diversas funções dentro das organizações, são elas planejar, organizar, liderar e controlar.

Planejar significa que os administradores pensam antecipadamente em seus objetivos e ações, e que seus atos são baseados em algum método, plano ou lógica, e não em palpites. São os planos que dão a organização seus objetivos e que definem o melhor procedimento para alcançá-los.

Organizar é o processo de arrumar e alocar o trabalho, a autoridade e os recursos entre os membros de uma organização, de modo que eles possam alcançar eficientemente os objetivos da mesma.

Liderar significa dirigir, influenciar e motivar os empregados a realizar tarefas essenciais. Enquanto planejar e organizar lida com os aspectos mais abstratos do processo administrativo, a atividade de liderar é muito concreta: ela envolve o trabalho com pessoas.

Esta é a função de controlar, exercida pela administração, e que envolve três elementos principais: estabelecer padrões de desempenho; medir o desempenho atual; comparar esse desempenho com os padrões estabelecidos; e caso sejam detectados desvios, executar ações corretiva. Através da função controlar, o administrador mantém a organização no caminho escolhido (STONER; FREEMANN, 2010, p. 7).

O setor de agronegócios no contexto econômico do país é, sem dúvida, de suma importância. Isso se dá devido ao volume de recursos que movimenta, número de empregos que gera e por ser o setor primário da economia. Apesar de ter essa condição de setor primário, não tem garantias de recursos, subsídios ou preços juntos para os produtores. Por isso nesses novos tempos os produtores precisam ter competência na administração. E não achar que por serem os produtores de comida que não precisam administrar a sua propriedade (FLORES; RIES; ANTUNES, 2006).

Em relação aos demais segmentos da economia o setor agropecuário sempre foi atrasado, no sentido de utilização de novas tecnologias e técnicas administrativas. Mas essa característica já esta superada, no que diz respeito a sistemas de informação o setor hoje já esta no mesmo patamar dos demais segmentos (FLORES; RIES; ANTUNES, 2006).

Para Flores, Ries e Antunes (2006, p. 19) o conceito de administração rural esta relacionado com "a necessidade de controlar e gerenciar um número cada vez maior de atividades que podem ser desenvolvidas dentro de uma propriedade do setor agropecuário". Qualquer atividade que o produtor realizar dentro de sua propriedade estará ligada a administração rural. 
Os donos de propriedades rurais não podem ser chamados mais somente de "fazendeiros", mas sim de "empresários rurais". Conforme os autores:

[...] os chamados "empresários rurais" seriam aqueles proprietários de terras que exploram de maneira intensiva os recursos disponíveis e suas propriedades e que investem em tecnologia e em controle de informações, levando seu negócio de maneira empresarial e mantendo, assim, maior rentabilidade. Mas não é só isso: o verdadeiro empresário rural deve visar também que sua propriedade cumpra a função social da terra, cumpra a função ecológica e de meio ambiente e que atinja os índices de produção determinados por órgãos governamentais (tais como Grau de Utilização da Terra GUT e Grau de Eficiência de Exploração GEE). Somente dessa forma é que este proprietário estará de bem com seu bolso e com aqueles que fiscalizam o que ele faz (FLORES; RIES; ANTUNES, 2006, p. 22).

A administração correta das atividades rurais é fundamental para que as propriedades rurais sobrevivam nesse mundo econômico competitivo. Assim como as empresas urbanas as rurais também precisam investir em controle de custos e estrutura administrativa. O capital movimentado nas empresas rurais tem um imobilizado muito maior do que as urbanas (FLORES; RIES; ANTUNES, 2006).

\section{IMPORTÂNCIA DA GESTÃO NA UNIDADE DE PRODUÇÃO FAMILIAR}

Para Gazzoni e Guber (2014, p. 238) "o agricultor necessita empreender soluções que contribuam para o estabelecimento de parceria, promovam a gestão participativa de toda a família e a busca constante de informações que permitam projetar tendências e aproveitar as oportunidades".

Nas propriedades rurais os dados, normalmente, estão armazenados na cabeça do produtor e nos membros de sua família, por isso se diferenciam de uma empresa capitalista. Eles possuem uma forma muito própria de administrar a sua propriedade (LIMA et al., 2005).

Lima et al. (2005), identifica que três concepções relacionadas a administração rural precisam ser trabalhadas com os agricultores. A primeira diz respeito a difusão das ferramentas de gestão para que eles passem a usa-las, a segunda esta ligada a preocupação com a assistência gerencial e econômica e a terceira esta embasada numa proposta de formação econômica e administrativa.

Conforme Lima et al. (2005) a assistência gerencial e econômica parte do pressuposto que a agricultura, por ser complexa, tem que ter uma visão empresarial. Na sua maioria, os agricultores não possuem essa visão, cabe aos técnicos a função de assisti-los para aumentar a produtividade, racionalizar custos e maximizar lucros. E uma formação econômica e administrativa para que possam perceber a importância da gestão e praticá-la. 


\section{AGRICULTURA FAMILIAR}

No Brasil o modelo produtivo por muitos anos foi o modelo patronal, onde a produção e o envolvimento familiar estavam em espaços distintos. As propriedades eram formadas por grandes extensões de terras, ostentada por poucos proprietários de grande representatividade social. As atividades desenvolvidas geralmente eram de cultivo de monocultura, café, feijão e cana de açúcar, ficando para os escravos os serviços, somente anos depois assumidos pelos camponeses.

Essa prática perdurou por muitos anos, foi considerada a principal base financeira do país. Mas recentemente o modelo denominado de agricultura familiar, passou a ganhar espaço e importância social na economia. Em linhas gerais, segundo Denardi (2001, p. 57), "os empreendimentos rurais têm duas características principais: eles são administrados pela própria família; e neles a família trabalha diretamente, com ou sem ajuda de terceiros".

A legislação brasileira estabelece as diretrizes para a formulação da Política Nacional da Agricultura Familiar e Empreendimentos Familiares Rurais na Lei 11.326 de 24 de julho de 2006 (BRASIL, 2006). A lei inclui a agricultura familiar como atividade econômica e apresenta a informação de que:

Art. $3^{\circ}[\ldots]$ considera-se agricultor familiar e empreendedor familiar rural aquele que pratica atividades no meio rural, atendendo simultaneamente, aos seguintes requisitos:

I - não detenha, a qualquer título, área maior do que 4 (quatro) módulos fiscais;

II - utilize predominantemente mão-de-obra da própria família nas atividades econômicas do seu estabelecimento ou empreendimento; III - tenha percentual mínimo da renda familiar originada de atividades econômicas do seu estabelecimento ou empreendimento, na forma definida pelo Poder Executivo;

IV - dirija seu estabelecimento ou empreendimento com sua família (BRASIL, 2006, texto digital).

A agricultura familiar tem grande importância para o desenvolvimento do país, nas estatísticas do censo de 2005/2006, onde se constatou que a agricultura familiar brasileira representa 4,3 milhões de estabelecimentos, significa $84,4 \%$ dos estabelecimentos agropecuários brasileiros. Também identificou que $70 \%$ dos alimentos consumidos pelos brasileiros são oriundos da agricultura familiar.

\section{MULHER NO MUNDO DA GESTÃO}

Para Gomes (2005, p. 3) na sociedade primitiva no lar se tecia a lã, se confeccionava o vestuário, as cerâmicas, se preparava o alimento, mantinha os animais domesticados e se cultivavam as plantações. O treinamento do homem 
era para as atividades "fora do lar", pois eram consideradas atividades que exigiam maior força física. As mulheres assumiam as atividades do lar, não podiam participar das atividades que eram consideradas masculinas.

Gomes (2005, p. 3) explica que "na antiguidade, a atribuição das tarefas domésticas exclusivamente as mulheres começou a solidificar-se como um aspecto decorrente da natureza do sexo feminino e como base para a rígida divisão do trabalho entre homens e mulheres." A Revolução Industrial veio representar uma etapa de progresso material, mas que discriminou o trabalho feminino. Elas podiam trabalhar em setores onde a remuneração era menor. Apenas no século $X X$ que alguns eventos contribuíram para aumentar a participação das mulheres no mercado de trabalho.

Historicamente o processo de inserção da mulher no mercado de trabalho mostra dificuldades, por aspectos culturais, salariais e questão de gênero. Nesse contexto a mulher na propriedade rural já não se limita mais na atuação nas atividades domésticas, que estão ligadas aos costumes, tradições, e valores herdados das sociedades patriarcais, segundo Wommer e Cassol (2014).

Mulheres atuam em cargos de chefia em organizações, têm a responsabilidade de comandar o seu destino. Da mesma maneira, no campo, o desafio é colocado para as mulheres, além de serem as detentoras da maternidade, com o papel de valorizar a afetividade, assume junto com o marido ou a família as atividades pertinentes a gestão (WOMMER; CASSOL, 2014).

Para Barbosa et al. (2011) algumas características particulares das mulheres, encorajar a participação de todos no trabalho, partilhar o poder e a informação, estimular, valorizar e motivar os demais para os afazeres, são atributos de mãe, mas que são levados para o mundo do trabalho. Esses fatores agregam maior desempenho no desenvolvimento das funções dentro da propriedade.

A realidade das mulheres dentro da agricultura familiar é de muito trabalho e pouco reconhecimento. As agricultoras brasileiras, ainda hoje, sofrem de invisibilidade social como trabalhadoras e como cidadãs. Seu trabalho é considerado uma "ajuda" dentro da família, enquanto o homem é considerado o verdadeiro "produtor rural"; conhecimentos e experiências das mulheres, principalmente no que se refere a produção de alimentos, são menosprezados; a representação publica da família é outorgada ao homem, esperandose que as mulheres permaneçam restritas ao mundo doméstico (BRASIL, 2012, p. 21).

Em vista que várias pesquisas já foram realizadas em outros meios onde a mulher tem um papel frente a gestão, mas no meio rural isso ainda é uma novidade. É importante ampliar o conhecimento sobre as relações de gênero na agricultura familiar. Enfatizando a importância da gestão, pois no atual 
contexto econômico o produtor rural precisa adquirir uma nova visão frente aos negócios.

\section{PROCEDIMENTOS METODOLÓGICOS}

Neste capítulo é abordado o tipo de pesquisa, com a sua definição quanto aos seus objetivos, a natureza da abordagem e os procedimentos técnicos. É importante salientar que a forma utilizada para obter a coleta de dados da pesquisa, resultou numa base de dados em acordo com os objetivos propostos.

Para identificar os aspectos que caracterizam o tipo de pesquisa, foi usada para definição quanto aos seus objetivos a forma exploratória.

A pesquisa exploratória tem como objetivo segundo Malhotra:

[...] prover a compreensão do problema enfrentado pelo pesquisador. A pesquisa exploratória é usada em casos nos quais é necessário definir o problema com maior precisão, identificar cursos relevantes de ação ou obter dados adicionais antes que se possa desenvolver uma abordagem (MALHOTRA, 2001, p. 105).

Para Malhotra (2001), a pesquisa exploratória tem por característica a flexibilidade e versatilidade em respeito aos métodos, pois não são usados protocolos e procedimentos formais de pesquisa. Dificilmente envolve questionários estruturados, grandes amostragens e planos probabilísticos.

Quanto a abordagem da natureza a pesquisa é qualitativa, Malhotra (2001, p. 155) descreve como, "metodologia de pesquisa não estruturada, exploratória, baseada em pequenas amostras, que proporciona insights e compreensão do contexto do problema". Para obtenção dos dados foi usado o método de entrevistas de profundidade, que constitui uma entrevista direta e pessoal, não estruturada, em que um entrevistador dialoga com o entrevistado para descobrir suas motivações, crenças, valores e sentimentos.

O método para definição da pesquisa quanto aos procedimentos técnicos foi o survey. Malhotra (2001, p. 179) define survey como método para obtenção das informações baseada num interrogatório, onde são feitas variadas perguntas sobre comportamento, atitudes, motivações, características e estilo de vida.

Os dados e informações foram obtidos através de uma entrevista semiestruturada, com cinco mulheres, que participam da gestão de propriedades rurais familiares do município de Westfália/RS. Destas, duas têm idade entre 20 e 30 anos, duas entre 30 e 50 anos e uma acima de 50 anos. Foi usada essa diferença de idade para que as informações coletadas apresentassem uma melhor percepção em relação aos principais desafios enfrentados por elas na gestão. 
O estudo ocorreu na cidade de Westfália/RS, que pertence ao centro do Rio grande do sul, colonizado por imigrantes alemães. Com um território de $63.702 \mathrm{~km}^{2}, 2.793$ habitantes (Censo 2010), sendo que destes $60 \%$ morando no meio rural. A base principal da economia provém do meio rural, destacando-se a produção leiteira, suinocultura, avicultura de corte e postura (WESTFÁLIA/ $\mathrm{RS})$.

O período de coleta de dados foi registrado nos meses de agosto e setembro de 2016, onde se buscou conhecer quais são os principais desafios que as mulheres enfrentam na gestão das suas propriedades, através de uma pesquisa aberta.

É importante manter uma discussão com relação ao desafio da participação feminina na gestão das propriedades rurais, como uma forma de clarear a visão sobre o atual cenário em que a mulher agrega a seu perfil, além da função de dona do lar, também a função de gestora. Elas estão conquistando seu espaço e provocando mudanças nos padrões de vida da sociedade onde estão inseridas.

\section{ANÁLISE DOS RESULTADOS}

A agricultura familiar é uma categoria composta por famílias que ao mesmo tempo são proprietárias, desempenham o trabalho e a gestão das propriedades. Essa característica traz consequências nas formas de produção e decisões nas relações econômicas e sociais. A importância para o país pode ser observada pelas estatísticas do censo do IBGE (2006), onde se contatou que a agricultura familiar brasileira representa 4,3 milhões de estabelecimentos, isto é $84,4 \%$ dos estabelecimentos agropecuários brasileiros.

Nos dados do censo IBGE (2009), das propriedades onde se pratica a agricultura familiar, os homens são responsáveis por $87,32 \%$ do total, enquanto elas são responsáveis por $12,68 \%$. Apesar de elas serem a minoria no que se refere as responsabilidades, participam de todas as atividades da propriedade, não são mais apenas donas de casa.

O município de Westfália, alvo do estudo, emancipou-se em 1996 do município de Teutônia e Imigrante, recebeu o nome em homenagem aos imigrantes, que na sua maioria são oriundos de uma região próxima da Holanda e que integra o atual estado Renânia do Norte Westfália. O município é formado pelas localidades de Linha Frank, Linha Schmidt, Berlim, Picada Moltke, Picada Bismark, Picada Horst, Köln e Linha Paissandu (WESTFÁLIA/ $\mathrm{RS})$.

O avanço das mulheres no processo de participação na gestão das propriedades rurais é significativo, pois há uma melhora na autoestima e autoconfiança delas em si mesmas. Isso está ligado a características da mulher, como flexibilidade, sensibilidade e espirito de cooperação. 
O estudo, cujas questões norteadoras investigam o desafio da participação da mulher na gestão das propriedades rurais familiares, além de apontar quais são os principais desafios, identifica o seu perfil. Outros pontos que também são evidenciados pelo levantamento de dados, procuram entender quais são as expectativas dos pais em relação ao papel da "filha" na propriedade, analisar como é a gestão delas na propriedade e também levantar algumas das principais dificuldades em relação à gestão.

Foram feitos cinco questionários com perguntas semiestruturadas, elaboradas previamente, para que não se fugisse do real propósito da pesquisa. As perguntas foram feitas pela pesquisadora às mulheres entrevistadas numa conversa informal.

Para facilitar o entendimento de algumas questões particulares de cada mulher entrevistada será designada uma letra junto da idade a cada uma delas. Da mais nova para a mais velha, "A-27", "T-27", "S-44", "M-46" e "R-60".

Para o primeiro objetivo da pesquisa foi feito um levantamento do perfil das mulheres e um breve relato da história da propriedade. As duas mulheres mais novas têm 27 anos (A-27 e T-27), casadas, cada uma tem um filho e a escolaridade é de segundo grau completo, as de meia idade são de 44 anos (S-44) e 46 anos (M-46), casadas, têm dois filhos e primeiro grau incompleto e a mulher mais velha tem 60 anos (R-60), casada, dois filhos e primeiro grau incompleto.

Nas propriedades T-27, S-44 e R-60, elas nasceram e se criaram nela, foram os pais ou avós que já iniciaram as atividades nesse local. A mulher A-27 foi morar na propriedade junto com o marido quando casaram e a mulher M-46, junto com o marido compraram uma área de terras e nela iniciaram uma nova propriedade.

No levantamento da questão sobre as atividades desenvolvidas na propriedade, em $100 \%$ delas, elas atuam somente na propriedade e não têm outra fonte de renda. Dentro das propriedades elas participam do todas as tarefas diárias, como relatou uma delas, "eu acho que eu tenho que tá junto, né". As atividades são com produção de leite, suínos, aves e terneiras, característica muito forte em muitas propriedades do município.

As mulheres iniciam muito cedo pela manhã suas atividades, relataram que às seis horas já estão de pé e junto com os maridos participam da lida, manejo e trato dos animais. Também fazem os serviços da casa, como cozinhar, limpar, arrumar e lavar roupas. Uma delas relatou que, além disso, tudo, não podia esquecer-se de ser mãe. Como todas são mães, sabemos que precisam dar atenção, carinho e tirar um tempo para ficar com seus filhos.

Uma característica que predominou nessas propriedades foi que, em apenas numa delas mora ela, o marido e os dois filhos. Nas outras moram elas com os maridos, filhos e têm os pais ou sogros que também ainda atuam nas rotinhas de produção da propriedade. Como são propriedades com um número 
maior de pessoas, isso muitas vezes não é fácil para convivência, pois são mais pessoas que opinam e participam da gestão.

Para introduzir o principal objetivo da pesquisa, questionou-se o que elas entendiam do significado da palavra "gestão". Todas sabiam de uma ou de outra forma o que isso significava, falaram sobre ter que fazer planejamento na propriedade, saber cuidar, gerenciar as entradas e saídas e ter clareza de onde a propriedade quer chegar. Algumas frases ditas por elas na entrevista que chamaram a atenção, "é que a gente sempre assim em conjunto senta e discute, então, o que que nós vamos fazer. O que que dá para melhorar ou o que nós vamos fazer agora. Se sobra algum dinheiro.", "é planejar, né", o que vamos plantar, como vamos plantar, se vamos criar mais novilhas. Sempre tem que planejar, para ter um rumo certo".

No segundo objetivo, referente às expectativas dos pais em relação ao papel da filha na propriedade, quando questionadas o que os pais sonhavam para elas na vida adulta, foram respostas diversas. Para a A-27, os pais achavam que o "negócio" era estudar e ir trabalhar em empresas, ficar na propriedade não era muito futuro. Hoje eles já têm uma visão muito diferente, como a filha está muito bem estruturada na propriedade, querem até que o neto a continue no futuro.

Para a T-27, já foi muito diferente, ela desde cedo demonstrou para os pais a intenção de continuar, eles a apoiaram e começaram a envolvê-la nas atividades. Para a mulher S-44 os pais incentivaram desde muito cedo a ficar na propriedade. Num detalhe da entrevista questionou-se se o pai teve alguma objeção por ela ser mulher e tocar a propriedade, a resposta foi a seguinte: "assim, pelo que eu noto ele não pensou muito assim... em... filho homem ou em... assim ele depositou a confiança em mim". Para a mulher M-46, o pai achava que ela precisava estudar, pois iria ganhar mais dinheiro fora. Hoje, também já mudou de ideia. Pensa para os netos estudarem e continuar na propriedade.

E para a mulher R-60, que é a mais velha, surpreendeu a resposta:

Sabe, antigamente era assim, os rapazes podiam. Eles tinham mais acesso ao estudo, tinha que administrar a propriedade. E as moças, se sabiam cozinhar e costurar, isso já bastava para elas. Mas aqui foi diferente, eu que fiquei aqui administrando praticamente com meu marido a propriedade e meu irmão foi trabalhar na firma, né.

Questionadas sobre o fato de os pais compartilharem os assuntos relacionados a propriedade, para $100 \%$ delas os pais dividem os assuntos. Para S-44, desde muito cedo os pais envolveram-na nas decisões da propriedade e apoiavam-na quando tinham melhorias a serem feitas. Um relato foi muito interessante, buscam a ajuda de terceiros. Esse auxílio pode ser fundamental numa tomada de decisão, pois clareia as ideias e auxilia no posicionamento 
perante uma indecisão. Essa é a mesma resposta da mulher R-60, os pais desde sempre trocaram ideias entre toda a família.

A M-46, mesmo não morando com os pais atualmente, assuntos são discutidos entre família, até os pais pedem opiniões aos filhos. A mulher T-27 explicou que, no inicio, quando ela começou a dividir as tarefas com os pais, eles falavam sobre assuntos relacionados ao dia a dia, a parte da gestão aconteceu com o tempo, mas hoje compartilham as decisões. A mulher A-27, hoje mora com a sogra, mas tem um entrosamento muito bem entre eles, por isso os assuntos são compartilhados.

Quanto aos pais autorizar as filhas a participar das decisões da propriedade, as respostas foram: para S-44 e M-46 os pais sempre autorizaram a participação nas decisões da propriedade, para R-60 os pais decidiam, mas eles sempre a envolveram nas atividades de rotina e ensinavam-na como funcionava a lida com os animais e a terra. Para A-27 quando ainda morava com os pais, eles não autorizavam ela a participar.

Na propriedade da T-27, foi feita uma divisão, os pais controlam a parte dos frangos e suínos, e ela com o marido ficam coma a parte leiteira. Cada um fica com uma área, só quando precisam tomar uma decisão maior dentro da propriedade ou quando envolve valores mais elevados, fazem uma reunião de família, para então decidir.

Apesar das particularidades de cada propriedade, é unanime a opinião que os pais têm hoje para as filhas, todos tem orgulho e torcem muito para que elas continuem na propriedade e tenham sucesso.

Para analisar como é a gestão delas na propriedade, terceiro objetivo do estudo, foram questionadas se uma mulher teria condições de gerir uma propriedade. Resposta da R-60: “Claro, iguais condições como o homem. Não tem diferença, entre o homem e a mulher para conduzir a propriedade. Eu pelo menos me sinto capaz de fazer aquilo que eu to fazendo". Assim foram todas as respostas, elas demonstrando que seriam capazes de gerir a propriedade. Mas também comentaram que não poderiam fazer isso sozinha, precisam de ajuda, poderia ser do marido, pais ou filhos.

Hoje, sabe-se que em alguns quesitos a mulher ainda sofre preconceitos. Sondadas se elas sofrem algum problema nesse sentido, relataram que antigamente isso era mais visível, que o pai mandava e a mãe não podia opinar muito. Uma delas até citou um exemplo, que a alguns anos atrás as mulheres não eram convidadas a participar de palestras, normalmente os homens que faziam essa parte, mas que hoje elas participam de igual maneira.

As famílias trabalham em conjunto, até mesmo na hora realizar as tarefas, não tem mais uma que seja de homens e outra da mulher, elas até dirigem os tratores. A mulher M-46 disse assim: "Eu ajudo, to do lado dele, e eu acho que tenho direito de opina". 
$\mathrm{Na}$ analise de como a mulher participa da gestão da propriedade, como isso é feito dentro da família e se ela toma decisões, foram $100 \%$ as mesmas respostas, elas participam em tudo na propriedade. Para tomar uma decisão normalmente a família se reúne e discute sobre o assunto, tem vezes que pedem orientações de terceiros.

Elas comentaram que é fundamental se informar bastante antes de tomar qualquer decisão, que envolva um investimento mais alto. "Agente vai atrás de informação, né, sempre aparecem coisas novas. Pede dicas, conversa muito sobre o assunto. Vê pontos positivos e negativos".

Surpreendeu bastante o quanto elas entendem do assunto, como elas se envolvem em tudo, como elas são inteligentes e cultas. Elas relataram assuntos sobre novas tecnologias, máquinas e equipamentos. Para elas é bem claro o quanto tem que saber sobre custos, entradas e saídas e a importância de um bom planejamento da propriedade.

Questionadas, se estão estudando, fazendo algum curso ou participam de palestras oferecidas pelas prefeituras, sindicatos, escolas ou empresas. Todas demonstraram sempre ser muito interessadas em participar de palestras, sabem um pouco de computação e acham que é muito importante se atualizar. A resposta de R-60, “Depois dos 60 anos eu comecei a fazer um curso de informática. Nunca tive acesso a essas coisas. Mais outra coisa, mais desafiadora, meu Deus, nem sei se vou conseguir, to tentando fazer carteira de motorista". Normalmente não se encontra uma mulher com tanta vontade de se atualizar, quando chega nessa idade, já se acomoda um pouco mais.

Com relação às propriedades terem indicadores gerenciais, todas tem pelo menos um caderninho ou uma agenda onde são anotados os custos principais. As duas mulheres mais novas tem um além, a A-27 tem uma planilha no computador onde faz o lançamento das entradas e saídas. E a T-27, sim, ela junto com o marido tem dois programas de gerenciamento, um deles é referente aos animais e o outro dos custos.

Para o quarto e último objetivo, foi perguntado quais as dificuldades que elas enfrentam na gestão da propriedade rural. A mulher S-44 relatou que sentiu muitas dificuldades no inicio da propriedade, pois não se tinha acesso a máquinas e tecnologia e que hoje isso tudo já esta mais fácil. Ela gostaria de ter é mais habilidade na computação, os filhos estão a ajudando, "muitos dizem aí eu já sô velha, né, mas eu acho que nunca é tarde para aprender alguma coisa".

Para a mulher M-46, fez o mesmo comentário relacionado a falta de tecnologia, mas o que deu maior preocupação foram as dívidas, "isso não foi fácil". A mulher R-60 disse que hoje a maior dificuldade para ela é o estudo, "eu gostaria de ter estudado mais. Para poder acompanhar".

A mulher A-27, fez pensar que gestão também envolve relacionamento com pessoas, ela disse que uma grande dificuldade que passou, foi a de aprender a conviver com as pessoas que já moravam na propriedade. Pois 
quando ela foi morar com o marido, tinha uma cultura na propriedade e ela teve que se adaptar.

E a mulher T-27, também comentou sobre esse assunto, que uma dificuldade foi "quebrar alguns tabus. Tu vem com uma cabeça nova, né. Tu quer explorar o mundo, né. Quer conhecer as coisas novas que tem para fazer, né".

\section{CONSIDERAÇÕES FINAIS}

A região do Vale do Taquari tem como característica a pequena propriedade rural familiar, mas que está em constante evolução. Como, em outros setores, na agricultura as mulheres também estão se igualando nos diretos e capacidades com os homens.

Houve avanços significativos nos últimos anos, afirmando as mulheres como capazes de realizar tarefas que antes eram masculinas, como, dirigir carros, tratores e operar máquinas e equipamentos.

As mulheres pesquisadas ajudam em todas as atividades pertinentes a propriedade e tem uma participação muito importante nas decisões e no gerenciamento. Como elas mesmas relataram que antigamente não era assim, mas conquistaram o seu espaço e valor.

Quando iniciei o estudo, tinha uma concepção um pouco diferente em relação ao que os pais desejavam a elas no futuro. Achei que na maioria das vezes eles iriam querer que as filhas estudassem, mas foi bem diferente. Eles incentivaram as filhas a continuar a propriedade e a envolveram junto com eles na produção.

Os desafios que elas enfrentam diariamente são ter um planejamento das atividades diárias, organizar a propriedade, entender sobre entradas e saídas, saber se a propriedade esta com resultados e também ter a habilidade de liderar e motivar as demais pessoas que vivem na propriedade.

Elas precisam saber lidar com os animais, entender de alimentação, medicação, tecnologias e operar máquinas. E, além disso, planejar a propriedade. Se forem fazer novos investimentos, como vão fazer, como pagar, quais sãos os custos. Participam ativamente da gestão da propriedade, elas junto com os demais integrantes da família opinam e discutem sobre as decisões a serem tomadas.

Hoje, a mulher rural tem vez e voz, e serve de exemplo de superação para as demais, uma vez que a lida no campo é muito exigente, pois não tem folgas em finais de semana ou férias. As mulheres tem a habilidade de conciliar os trabalhos produtivos com os trabalhos domésticos e a ainda com a função de ser mãe. 
A entrevista com as mulheres foi uma experiência que jamais poderei esquecer, elas tem uma vitalidade incontestável. Foi muito importante para elevar meu nível de aprendizado para a universidade, profissional e particular.

Entendeu-se um pouco mais sobre a cultura, particularidades e a evolução nos aspectos gerenciais das propriedades da região. Novos estudos poderão ser feitos, para dar continuidade a investigação sobre o comportamento da mulher nas "empresas rurais". Um assunto que seria muito interessante para discussão é sobre o "empoderamento da mulher na nova propriedade rural".

\section{REFERÊNCIAS}

BARBOSA, F. C. et al. Empreendedorismo Feminino e Estilo de Gestão Feminina: estudos de casos múltiplos com empreendedoras da cidade de Aracajú/Sergipe. Revista da Micro e Pequena empresa, São Paulo, v. 5, n. 2, p. Disponível em: <http:// www.spell.org.br/documentos/ver/5898/empreendedorismo-feminino-e-estilode-gestao-feminina--estudo-de-casos-multiplos-com-empreendedoras-na-cidade-dearacaju-----sergipe>. Acesso em 27 abr. de 2016

BRASIL. Lei n ${ }^{\circ} 11.326$, de 24 de julho de 2006. Estabelece as diretrizes para a formulação da Politica Nacional da Agricultura Familiar e Empreendimentos Familiares Rurais. Disponível em: < http:/ /www.planalto.gov.br/ccivil_03/_ ato2004-2006/2006/lei/111326.htm>. Acesso em 27 abr. de 2016

BRASIL. Ministério do Desenvolvimento Agrário. Plano Safra da Agricultura Familiar 2012/2013. Brasília, jun.2012. Disponível em: <http:/ / portal.mda.gov.br/ plano-safra/arquivos/view/Cartilha_Plano_Safra.pdf $>$. Acesso em 27 de abr. de 2016.

BRASIL. Secretaria de Políticas para as Mulheres. Revista do Observatório Brasil da Igualdade de Gênero: edição especial, Brasília, v.2, n.4, dez. 2012. Disponível em: $<$ http://www.observatoriodegenero.gov.br/revista-observatorio2-30-11-final1.pdf $>$. Acesso em 27 abr. de 2016.

CHIAVENATO, Idalberto. Introdução a Teoria Geral da Administração. $9^{\circ}$ edição. São Paulo: Editora Manole, 2014.

DENARDI, Reni. Agricultura Familiar e Politicas Publicas: alguns dilemas e desafios para o desenvolvimento rural e sustentável. In. Agroecol. e Desenv. Rur. Sustent., Porto Alegre, v. 2, n. 3, 2001. P. 56-62. Artigo. Disponível em: <http:/ /www. emater.tche.br/docs/agroeco/revista/ano2_n3/revista_agroecologia_ano2_num3_ parte12_artigo.pdf>. Acesso em: 27 abr. de 2016.

FLORES Aécio Witchs; RIES, Leandro Reneu; ANTUNES, Luciano Medici. Gestão Rural. Porto Alegre. 2006.

GAZZONI, André; GUBERT, José Eduardo. Importância na Unidade de produção Familiar. In: COTRIN, Décio (Org). Desenvolvimento rural e agricultura familiar. v. 3. Porto Alegre: Emater/RS-Ascar, 2014. p. 237-251. E-book. Disponível em: <http:/ / 
www.emater.tche.br/site/arquivos_pdf/teses//E_Book3.pdf>. Acesso em: 04 mai. 2016.

GOMES, Almiralva Ferraz. O outro no trabalho: Mulher e Gestão. Rege Revista de Gestão da USP. v. 12, n.3, p. 1-9, julho/setembro 2005. São Paulo. Disponível em: <http://www.revistas.usp.br/rege/article/view/36522/39243>. Acesso em 04 mai. de 2016.

IBGE. Censo Agropecuário 2005/2006. Rio de Janeiro: IBGE. 2006.

IBGE. Censo Agropecuário 2006. Agricultura Familiar. Brasil, Grandes Regiões e Unidades da Federação. Brasília/Rio de Janeiro: MDA/MPOG. 2009.

KWASNICKA, Eunice Lacava. Introdução a Administração. São Paulo: Editora Atlas, 1995.

LIMA, Arlindo Jesus. P de. et al. Administração da unidade de produção familiar, modalidade de trabalho com Agricultores. $3^{\circ}$ edição. Ijuí-RS: Editora Unijui, 2005.

MALHOTRA, Naresh K.. Pesquisa de Marketing. $3^{\circ}$ edição. Porto Alegre: Editora Artmed, 2001.

MONTANA, Patrick J.. Administração. $2^{\circ}$ edição. São Paulo: Editora Saraiva, 2003.

STONER, James A. F.; FREEMANN, R. Edward. Administração. $5^{\circ}$ edição. Rio de Janeiro: Prentice Hall do Brasil, 1999.

WESTFALIA, Prefeitura Municipal de Westfália/RS. Disponível em: <http:/ /www. westfalia.rs.gov.br>. Acesso em 14 set. 2016.

WOMMER, Dulcenéia H.; CASSOL, Claudionei Vicente. A participação Feminina na Gestão da Propriedade Rural: cuidado que qualifica e humaniza. In: COTRIN, Décio (Org). Desenvolvimento rural e agricultura familiar. v. 3. Porto Alegre: Emater/RSAscar, 2014. p. 469-493. E-book. Disponível em: <http://www.emater.tche.br/site/ arquivos_pdf/teses//E_Book3.pdf>. Acesso: 04 mai. 2016. 